\title{
The Effectiveness of a Brief Self-Compassion Intervention Program on Self-Compassion, Positive and Negative Affect and Life Satisfaction
}

\author{
Archontia Mantelou, Eirini Karakasidou \\ Institution for Counseling and Psychological Studies (ICPS College), University of Central Lancashire, Athens, Greece \\ Email: andymantelou@hotmail.com
}

How to cite this paper: Mantelou, A., \& Karakasidou, E. (2017). The Effectiveness of a Brief Self-Compassion Intervention Program on Self-Compassion, Positive and Negative Affect and Life Satisfaction. Psycho$\log y, 8,590-610$.

https://doi.org/10.4236/psych.2017.84038

Received: February 2, 2017

Accepted: March 25, 2017

Published: March 28, 2017

Copyright (c) 2017 by authors and Scientific Research Publishing Inc. This work is licensed under the Creative Commons Attribution International License (CC BY 4.0).

http://creativecommons.org/licenses/by/4.0/ (c) (i) Open Access

\begin{abstract}
Self-compassion (Neff, 2003b) is a newly developed construct of positive psychology while a plethora of studies has highlighted its beneficial outcomes on people's psychological prosperity. This study aimed to explore the effectiveness of a brief self-compassion training program on self-compassion, life satisfaction and positive and negative affect as well as to contribute new knowledge by investigating whether changes in self-compassion can significantly predict changes in positive affect. A sample of 42 students of Social Sciences, randomly assigned to either the intervention $(\mathrm{N}=20)$ or the control group $(\mathrm{N}$ $=22$ ) group where the first group participated in a psycho-educational training program aiming to train them to be more self-compassionate in challenging situations whilst the control group received no training. The results that revealed through the three different questionnaires (Self-Compassion Scale, Life Satisfaction Scale and Positive and Negative Affect Scale) that both groups completed before and after the completion of the program, showed that the intervention group indeed indicated increases in self-compassion, life satisfaction as well as positive affect scores and decrease in negative affect scores, compared to the control group which reported no changes. Furthermore, participants' increases in self-compassion levels strongly predicted increases in positive affect levels, meaning that those who are high self-compassionate have also high positive affect. These findings suggest the importance of selfcompassion on psychological well-being, testing through the implementation of specific intervention programs. Other possible implications and recommendations for future research are also considered.
\end{abstract}

\section{Keywords}

Self-Compassion, Intervention Program, Positive and Negative Affect, 


\section{Introduction}

First of all, as Germer (2009) stated, "compassion comes from the Latin roots com (with) and pati (suffer)" (p. 33). According to Neff's (2003a, b) definition, self-compassion involves being kind, warm and standing with understanding toward yourself when you suffer, fail or feel inadequate, rather than criticizing and blaming yourself or ignoring the pain and negative feelings. Therefore, compassion, whether addressed to others or to the self, necessarily includes three elements: link with pain, awareness of the pain and intense desire for reduction or elimination of discomfort instead of desire for avoidance.

Self-compassion entails three basic interacting components (Neff, 2003a; Neff, 2012): self-kindness versus self-judgment, common humanity versus isolation and mindfulness versus over-identification. Self-kindness is the ability to be warm and sympathetic to oneself when suffering, trying to soothe their pain instead of holding an angry and furious attitude. Common humanity (Neff, 2012) refers to the realization that the individual is not alone within the defect. The situation experienced by a person, no matter how painful it is, is still part of human nature and we must not isolate them from the community. Mindfulness is about the uncritical attitude towards the thoughts, feelings and actions of a person without, however, trying to omit them or-as Guy Armstrong (as cited in Germer, 2009) emphasized-"knowing what you are experiencing while you are experiencing it".

\subsection{Self-Compassion and Psychological Well-Being}

There is a proliferation of research over the past decade highlighting the association of self-compassion with psychological well being (Barnard \& Curry, 2011; Krieger et al., 2015; Neff, 2009) and functioning (Birnie, Speca, \& Carlson, 2010; Neff, Kirkpatrick, \& Rude, 2007). There is strong evidence that self-compassion constitutes a factor predicting psychological well being and promoting positive mental health benefits (Neff, 2004; Smeets et al., 2014). Neely et al. (2009) defined well-being as low stress, negative affect and high life satisfaction. More specifically, psychological well-being, based on Zessin's, Dickhauser's, \& Garbade's (2015) insightful meta-analysis, seems to be a key factor for the eudemonia of people leading to a meaningful life and functioning and revealed a strong correlation of self-compassion and psychological well-being. Additionally, the same study indicated that subjective well-being entails cognitive well-being, which is characterized by the notion of life satisfaction and affective well-being, which is characterized by the notion of positive and negative effect. They finally concluded that those two concepts of psychological and subjective well-being have strong commonalities and generally share the same ground of well-being.

Higher scores on self-compassion seem to lead to higher levels on positive 
mind-states, such as life satisfaction, happiness, connectedness, self-confidence, optimism, curiosity, positive affect and gratitude (Heffernan, Griffin, McNulty, \& Fitzpatrick, 2010; Hollis-Walker \& Colosimo, 2011; Neff, Rude, \& Kirkpatrick, 2007; Neff, 2009). On the other hand, they seem to be related to lower levels on negative mind-states, such as anxiety and depression (Barnard \& Curry, 2011; Yang, 2016), stress, rumination, thought suppression, perfectionism and shame (Macbeth \& Gumley, 2012; Neff \& Lamb, 2009), linking thus self-compassion with psychopathology.

Also, self-compassion proved to enhance resilience by controlling people's responses to stressful and unpleasant events. According to a series of studies of Leary et al. (2007), participants were asked to recall a negative and distressing situation, experience or event and reflect on that. Evidence showed that participants who were more self-compassionate indicated fewer negative feelings, accepting thoughts more and took their own responsibility for what had happened compared to those who were less self-compassionate.

\subsubsection{Positive and Negative Affect}

Self-compassion also relates to core constructs in health and well-being (more specifically emotional well-being) (Neff \& Lamb, 2009) and is associated with positive and negative effect, according to Krieger et al. (2015). Their investigation showed that self-compassion was positively correlated with positive affect and negatively correlated with negative affect (Neff, Rude, \& Kirkpatrick, 2007; Neff \& Vonk, 2009) while the same results revealed by Arimitsu \& Hofmann (2015), arguing that self-compassion leads to increase of positive automatic thoughts which in turn lead to higher levels of life satisfaction and lower levels of anxiety. So, it is so far confirmed by literature that self-compassion is associated with reduced negative affect (Neff, Kirkpatrick, \& Rude, 2007) and increased positive affect and happiness (Neff et al., 2007). Nevertheless, Barnard \& Curry (2011) highlighted the need for further future interventions focusing on the increase of self-compassion and potentially the increase of positive and reduce of negative effect.

\subsubsection{Life Satisfaction}

A plurality of studies has concluded that self-compassion enhances and correlates with positive mind-states such as life satisfaction (Neely, et al., 2009; Seligowski, Miron, \& Orcutt, 2014; Van Dam, Sheppard, Forsyth, \& Earleywine, 2011; Wei, et al., 2011; Yang, 2016). More specifically, according to a recent study focusing on the role of self-compassion on life satisfaction and hope (Yang, Zhang, \& Kou, 2016) and testing a sample of Chinese adults demonstrated that self-compassion indeed is positively associated with life satisfaction and added that hope plays a mediating role between self-compassion and life satisfaction.

\subsection{Self-Compassion Positive Intervention Programs}

Generally, recent meta-analytic studies have determined the importance and 
contribution of psychological interventions in the field of positive psychology (Bolier et al., 2013; Giannopoulos \& Vella-Brodrick, 2011; Seligman, Steen, Park, \& Peterson, 2005). More specifically, they examined the effects of positive interventions compared to placebo control groups and their empirical validation revealed increases in happiness and decreases in depression for the experimental groups while they concluded that positive interventions are undeniably effective and have a significant impact on psychological well-being and mental health as well as in relieving peoples' suffering.

Thus, there is the need for interventions that will raise self-compassion, as it has been proved that self-compassion can be cultivated and learned (Neff \& Costigan, 2014). A study of Shapira \& Mongrain (2010), asking participants to write a compassionate letter to themselves once a day for a period of one week regarding a stressful experience, indicated less depressive symptoms and an increase in happiness levels compared to the control group who did not receive any training.

Moreover, Smeets et al. (2014) aiming to examine the effectiveness of a newly developed 3-week self-compassion intervention program consisting of three meetings, tested a sample of female students. The intervention group showed significantly greater scores in self-compassion, mindfulness, optimism and self-efficacy, as well as significantly greater decreases in rumination in comparison to the control group, while both groups indicated increased levels of life satisfaction. Nevertheless, no significant changes of positive and negative affect were found for intervention group. So, it was supported that brief self-compassion training can lead to significant changes in well-being.

Recently, Germer \& Neff (2013) developed an 8-week Mindful Self-Compassion training program in order to teach participants to be more self-compassionate. The program includes techniques such as loving-kindness, affectionate breathing, self-compassionate letter etc and participants reported increases in self-compassion (by 43\%), compassion for others, mindfulness and life satisfaction, as well as significant decreases in depression, anxiety, stress, and emotional avoidance, while those results were consistent to the ones acquired one year after. A similar research of Bluth, Roberson, \& Gaylord (2015) explored the effects of mindfulness intervention on emotional well-being in a sample of adolescents. The progress between pre-training and post-training were related to improvements in mindfulness, self-compassion, stress and life satisfaction while they demonstrated the need for future research in investigating self-compassion as a core predictor of emotional well-being.

Although mindfulness-based programs can promote self-compassion, they mainly focus on enhancing mindfulness rather than self-compassion skills and thus there is the need for the development of interventions that specifically aim at the increase of self-compassion (Neff \& Germer, 2013). Nevertheless, both mindfulness and self-compassion skills seem to be strong predictors of wellbeing (Baer, Lykins, \& Peters, 2012). All things considered, it was discussed the connection of the theoretical part of such studies with the practical part as they 
can potentially enhance and cultivate self-compassion and in turn promote psychological well-being.

\subsection{Research Question and Hypotheses}

The significance of self-compassion on aspects of psychological well-being and more specifically on positive and negative affect and on life satisfaction was supported. It was also recognized that there is a need for implementation of positive intervention programs aiming at teaching and training people in order to be more self-compassionate when facing demanding situations. Nevertheless, what was found to need further investigation is whether changes in self-compassion can predict changes in positive affect. Although a large body of studies indicated a strong relation between self-compassion and emotional well-being, this relation still needs to be examined through a self-compassion intervention program. As a result, the main research question of this study goes as follows: Can self-compassion intervention predict positive affect? Secondary, the selfcompassion intervention aimed to investigate the following hypotheses:

1) The effectiveness of self-compassion intervention. Will there be an increase in self-compassion levels in the intervention group?

2) Will there be an increase in positive affect and a decrease in negative effect in the intervention group?

3) Will there be an increase in life satisfaction in the intervention group?

\section{Method}

\subsection{Design}

This study employed 2 (Group: Self-compassion Intervention VS Control) $\times 2$ (Time: Pretest VS Posttest) mixed ANOVAs, with group being manipulated between groups and time being manipulated within groups, as well as paired samples t-tests and a linear regression for the analysis of the data. In particularly, the independent variables were self-compassion and the procedure of the brief self-compassion training program through specific exercises, lasting 5 weeks. The dependent variables were self-compassion, life satisfaction as well as positive and negative effect.

\subsection{Participants}

In the current research, a sample population comprised 42 students of Social Sciences at Panteion University of Greece, 15 of which were males and 27 females. They ranged in age from 19 to 30 years old with mean age 22.93 (SD = 2.68) and the method of recruitment was by opportunity sampling through brochures that announce a study examining the impact of Theory of Emotions on psychological well-being. Participation in the survey was voluntary, based on informed consent and ethnic composition was 100\% Greek. All participants were randomly divided into two groups, either the self-compassion intervention group $(\mathrm{N}=20)$ or the control group $(\mathrm{N}=22)$ in which students just fill out the same questionnaires with the first group but without receiving any training. In 
turn for their participation, participants received course credits. The present study was conducted according to the British Psychological Society ethical guidelines for research.

\subsection{Materials}

For the purpose of this study, a consent form as well as a briefing and a debriefing sheet were provided to the participants. All participants also filled out a number of self-report measures one week before and one week after the threeweek intervention. In order for participants' anonymity and privacy to be secured, there were codes match for each participant. Greek versions were used for all measures and the questionnaires were distributed to the participants counterbalanced.

\subsubsection{Positive and Negative Affect Schedule}

The PANAS Questionnaire (Watson, Clark, \& Tellegen, 1988) that was provided in its Greek version, comprises 20 items with two dimensions, with 10 items for positive and 10 items for negative affect (e.g. "Active", "Disturbed"), using a modified Likert-type scale, ranging from 1 (very slightly or not at all) to 5 (extremely). For each sub-scale, total scores range from 10 to 50. Higher scores demonstrate greater positive or negative effect. Internal consistency reliability in the present study was $\alpha=0.72$ for positive affect and $\alpha=0.73$ for negative effect.

\subsubsection{Life Satisfaction Scale}

Participants received the Diener's Satisfaction with Life Scale (Diener, Emmons, Larsen, \& Griffin, 1985), a five-item measure of global life satisfaction (e.g., "In most ways, my life is close to my ideal") that has been found to have good internal reliability, test-reliability, and validity. It was provided in its Greek version translated by Malikiosi-Loizos \& Anderson (1994). Internal consistency reliability in the present study was $\alpha=0.89$.

\subsubsection{Self-Compassion Scale (SCS) (Mantzios, Wilson, \& Giannou, 2015; Neff, 2003)}

Participants were given the 26-item Self-Compassion Scale (SCS, Neff, 2003) that was provided in the Greek version translated by Mantzios et al. (2015) and includes the 5 item Self-Kindness subscale (e.g., "I try to be understanding and patient toward aspects of my personality I don't like"), the 5-item Self-Judgment subscale (e.g., "I'm disapproving and judgmental about my own flaws and inadequacies"), the 4-item Common Humanity subscale (e.g., "I try to see my failings as part of the human condition"), the 4-item Isolation subscale (e.g., "When I think about my inadequacies it tends to make me feel more separate and cut off from the rest of the world"), the 4-item Mindfulness subscale (e.g., "When something painful happens I try to take a balanced view of the situation"), and the 4-item Over-Identification subscale (e.g., "When I'm feeling down I tend to obsess and fixate on everything that's wrong."). Responses are given on a 5-point scale from "Almost Never" to "Almost Always". Mean scores on the six subscales 
are then averaged (after reverse-coding negative items) to create an overall self-compassion score ranging from 26 to 130 . Higher scores correspond to higher levels of self-compassion. In the current research, internal consistency reliability was found to be $\alpha=0.91$.

Furthermore, participants were asked to answer in some demographic questions related to their age, gender and educational status.

\subsection{Procedure}

The present study was approved by the ICPS committee associated with the University of Central Lancashire (UCLAN). After the announcement of the study through flyers, I informed the tutors about the nature and purpose of the study and asked for their permission for the conduct of the meetings.

\subsubsection{Meeting 1: Baseline Assessment}

During the first meeting with the participants they were all asked to participate voluntarily in a survey examining the impact of Theory of Emotions on psychological well-being and they were informed about the confidentiality of their data and their right to withdraw from the study at any time. All participants received a booklet consisting of 1) the consent form, including some demographic characteristics and the participants' personal code and 2) the three different questionnaires. After the completion of the booklet they were randomly assigned to two groups: either the control $(\mathrm{N}=22)$ or the experimental group $(\mathrm{N}=20)$. The experimental group was informed that the program has a psycho-educational purpose aiming at training participants in the construct of self-compassion and that 4 more meetings are required once a week, lasting approximately $90 \mathrm{mi}-$ nutes each, if they still want to participate. The control group was also informed that one more meeting after four weeks is required, lasting approximately half an hour.

\subsubsection{Meeting 2-4: Self-Compassion (SC) Intervention Group}

The techniques and exercises that were implemented during the program were based on Neff's structured research (Neff \& Germer, 2013). It consisted of three weekly meetings where participants meet once a week for 90 minutes in the evening. Each session of the program focused on a specific topic.

\subsubsection{Understanding the Concept of Self-Compassion}

At the beginning of the first group meeting, a short introductory presentation regarding the main points of self-compassion took place. More specifically, during the presentation the different dimensions of self-compassion as well as its connection with self-esteem, well-being and important aspects of life were briefly described. The first exercise required from the participants to recall a suffering moment and the way they treated themselves at that time. Then they were asked to write down ways they would treat a friend having a similar suffering moment as well as what they would need in order to be more comforted. A discussion followed the exercise and at the end of the first session, participants were given 
their next week exercise which was the daily writing of a self-compassion journal which would include their weaknesses or difficult events, in order to improve the expression of emotions, thoughts and feelings.

\subsubsection{Role Playing According to a Scenario}

During the second meeting, participants completed some questions regarding the previous homework assignment, in order to confirm their commitment to the procedure, and their experiences on the exercise given were discussed. Furthermore, a role playing according to a scenario took place in which participants were divided into groups and they impersonated the criticizer, the criticized and the compassionate observer. The aim was to identify someone's feelings through those different aspects of acting. After that, participants reflected on the exercise. The self-compassion journal writing was given again to participants as homework exercise.

\subsubsection{Self-Compassion Letter}

During the third meeting, after the discussion and reflection on the previous week assignment, participants explored self-compassion through writing a letter to themselves about their future personal improvements from the perspective of a kind and compassionate friend. They shared their experiences about the letter while a general discussion of the program followed. Finally people we asked to evaluate the intervention.

\subsubsection{Meeting 5: Final Assessment}

All participants were asked to respond to the three different questionnaires again and we thanked them for their participation. A debriefing form, including the exact purpose and goals of the study was distributed to them.

\section{Results}

For the purposes of this study, the results from raw data that were collected through the questionnaires were analyzed. In particularly, the means and standard deviations of life satisfaction, as well as the positive and negative affect and self-compassion scores at pre-test measurements were calculated for all participants. What is more, the correlations between them were analyzed in order to check for variables' inter-correlations indicating that correlations were generally within the small to medium range and they are presented in Table 1.

A two-tailed Pearson's correlation revealed a medium, positive and significant correlation between life satisfaction and positive affect measures $(r=0.49, p<$ $0.001)$. A medium, positive and significant correlation between life satisfaction and self-compassion measures was also revealed $(r=0.39, p=0.010)$ as well as a medium, negative and significant correlation between negative affect and self-compassion $(r=-0.31, p=0.046)$. No significant correlations were reported between life satisfaction and negative affect measures $(r=-0.20, p=0.194)$, between positive and negative affect measures $(r=-0.19, p=0.223)$ as well as between positive affect and self-compassion measures $(r=0.29, p=0.059)$. 
As presented in Table 2, the mean scores and standard deviations at pre and post-test measures of life satisfaction, as well as the positive and negative affect and self-compassion variables for intervention and control group were calculated separately.

A series of One-Way Independent samples ANOVAs was conducted in order to examine whether there were significant differences between the self-compassion intervention group and the control group at pre-test measures. ANOVAs revealed no significant differences between groups at any of the pre-test measures. More specifically, no group differences were indicated for life satisfaction scores $[F(1,40)=1.37, p>0.05]$, for positive affect $[F(1,40)=1.02, p>0.05]$, for negative affect $[F(1,40)=0.49, p>0.05]$ and for self-compassion $[F(1,40)$ $=2.50, p>0.05$ ].

Additionally, a series of paired samples $t$-tests was employed to examine pre and post changes in study outcomes for each group separately.

More specifically, two-tailed paired samples $t$-tests revealed that there was a significant increase in life satisfaction scores $[t(19)=-5.47, p<0.001]$, in positive affect scores $[t(19)=-3.01, p=0.007]$, and in self-compassion scores [ $t(19)$ $=-4.42, p<0.001]$ as well as a significant decrease in negative affect scores $[t$ $(19)=4.41, p<0.001]$ for all participants of the intervention group.

Table 1. Mean scores, standard deviations ( $\mathrm{SD} s$ ) and bivariate correlations between the variables at pre-test $(\mathrm{N}=42)$.

\begin{tabular}{ccccc}
\hline & Life satisfaction & Positive affect & Negative affect & Self-compassion \\
\hline Life satisfaction & -- & $0.49^{* *}$ & -0.20 & $0.39^{*}$ \\
Positive affect & & -- & -0.19 & 0.29 \\
Negative affect & & & -- & $-0.31^{*}$ \\
Self-compassion & & & & -- \\
M & 22.64 & 33.95 & 20.93 & 78.52 \\
SD & 5.60 & 6.09 & 6.76 & 16.0 \\
\hline
\end{tabular}

Note: ${ }^{\star} p<0.05 ;{ }^{* *} p<0.001$.

Table 2. Mean scores and Standard Deviations at pre and post test measures for all variables of the two groups.

\begin{tabular}{ccccccccc}
\hline & \multicolumn{2}{c}{ Self-compassion Intervention group $(\mathrm{N}=20)$} & \multicolumn{3}{c}{ Control group $(\mathrm{N}=22)$} \\
\cline { 2 - 8 } & \multicolumn{2}{c}{ Pretest } & \multicolumn{2}{c}{ Posttest } & \multicolumn{2}{c}{ Pretest } & \multicolumn{2}{c}{ Posttest } \\
\cline { 2 - 8 } & $\mathrm{M}$ & $\mathrm{SD}$ & $\mathrm{M}$ & $\mathrm{SD}$ & $\mathrm{M}$ & $\mathrm{SD}$ & $\mathrm{M}$ & $\mathrm{SD}$ \\
\hline LS & 23.70 & 5.00 & 28.20 & 4.91 & 21.68 & 6.05 & 22.23 & 5.50 \\
PA & 34.95 & 5.48 & 39.40 & 6.02 & 33.05 & 6.60 & 32.91 & 5.07 \\
NA & 21.70 & 7.11 & 15.10 & 5.67 & 20.23 & 6.52 & 20.14 & 6.15 \\
SC & 82.55 & 18.15 & 92.70 & 13.98 & 74.86 & 13.12 & 76.27 & 13.21 \\
\hline
\end{tabular}

${ }^{\star}$ Note: $\mathrm{LS}=$ life satisfaction, $\mathrm{PA}=$ positive effect, $\mathrm{NA}=$ negative effect, $\mathrm{SC}=$ self-compassion, $\mathrm{M}=$ mean scores, $\mathrm{SD}=$ standard deviation. 
Additionally, two-tailed paired samples $t$-tests revealed that there was no significant differences in life satisfaction scores $[t(21)=-1.01, p=0.322]$, in positive affect scores $[t(21)=0.15, p=0.875]$, in negative affect scores $[t(21)=0.13$, $p=0.894]$ as well as in self-compassion scores $[t(21)=-1.46, p=0.159]$ for all participants of the control group.

Moreover, in order to determine whether the self-compassion intervention group reported greater well-being improvements than the control group, outcomes were analyzed using a series of 2 (Group: Self-compassion Intervention VS Control) $\times 2$ (Time: Pretest VS Posttest) mixed ANOVAs, with group being a between-subjects factor and time being a within-subjects factor.

\subsection{Self-Compassion}

There was a significant main effect of the time of self-compassion (pretest-posttest), $F(1,40)=23.04, p<0.001, \mathrm{Eta}^{2}=0.37(37 \%)$. According to the examination of the estimated marginal means, this effect informs us that if we ignore the group (intervention-control), the time of self-compassion (pretest-posttest) will still be rated significantly different (see Figure 1).

There was a significant main effect of group (intervention-control), $F(1,40)=$ $7.59, p=0.009, \mathrm{Eta}^{2}=0.16(16 \%)$. According to the examination of the estimated marginal means, this effect is indicative that if we ignore all other variables, the intervention group will be significantly different to control group (see Figure 1).

There was a significant interaction between the time of self-compassion (pretest-posttest) and the group (intervention-control), $F(1,40)=13.18, p=0.001$, $\mathrm{Eta}^{2}=0.25(25 \%)$. This effect informs us that the time of self-compassion (pretest-posttest) had a different effect on the group (intervention-control). The CI

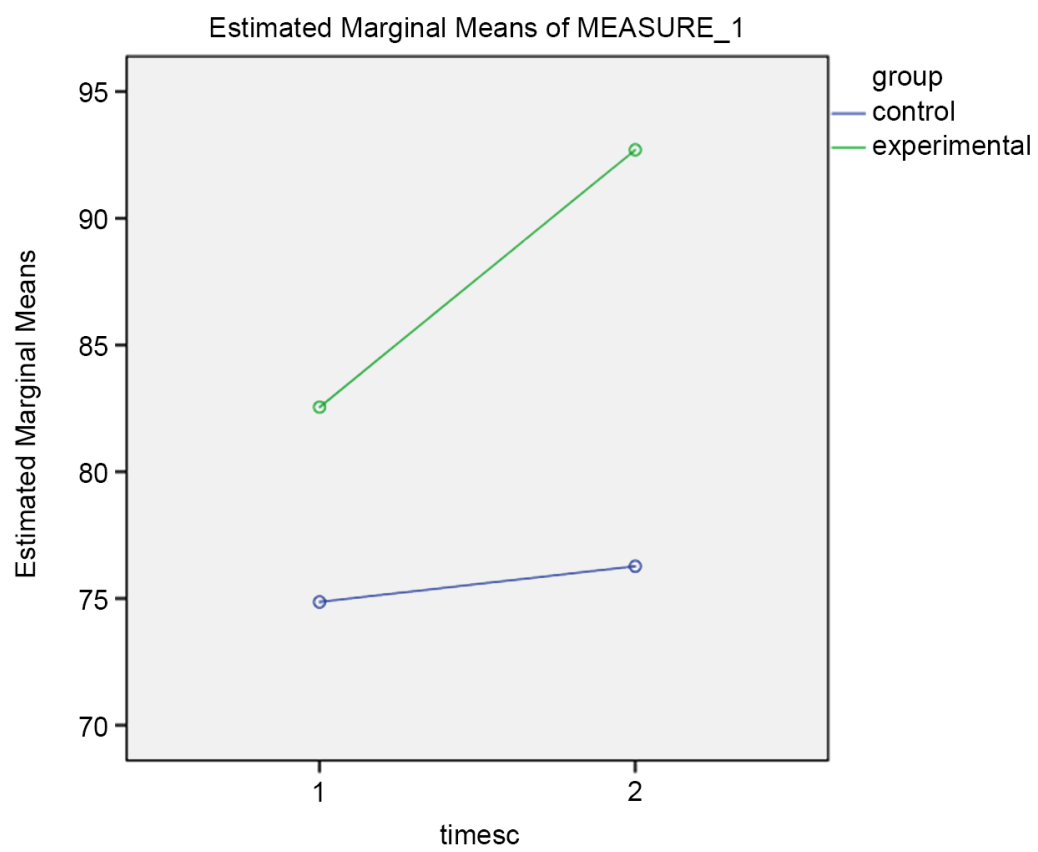

Figure 1. Estimated marginal means for self-compassion. 
Graph below indicated greater self-compassion differences for intervention than the control group (see Figure 2).

A two-tailed independent samples t-test showed a significant change between the two groups, self-compassion intervention and control group with the intervention group demonstrating greater scores in self-compassion rather than the control group $[t(40)=-3.91, p<0.001]$. The homogeneity of variance assumed by Levene's test $(F=0.063, p=0.804)$.

\subsection{Life Satisfaction}

There was a significant main effect of the time of life satisfaction (pretest-posttest), $F(1,40)=27.32, p<0.001, \mathrm{Eta}^{2}=41(41 \%)$. According to the examination of the estimated marginal means, this effect indicates that if we ignore the group (intervention-control), the time of life satisfaction (pretest-posttest) will be still rated significantly different (see Figure 3 ).

There was a significant main effect of group (intervention-control), $F(1,40)=$ 6.24, $p=0.017, \mathrm{Eta}^{2}=0.13(13 \%)$. According to the examination of the estimated marginal means, this effect tells us that if we ignore all other variables, the intervention group will be significantly different to control group (see Figure 3).

There was a significant interaction between the time of life satisfaction (pretest-posttest) and the group (intervention-control), $F(1,40)=16.78, p<0.001$, $\mathrm{Eta}^{2}=0.30(30 \%)$. This effect shows that the time of life satisfaction (pretestposttest) had a different effect on the group (intervention-control). The CI Graph below indicated greater life satisfaction differences for intervention than the control group (see Figure 4).

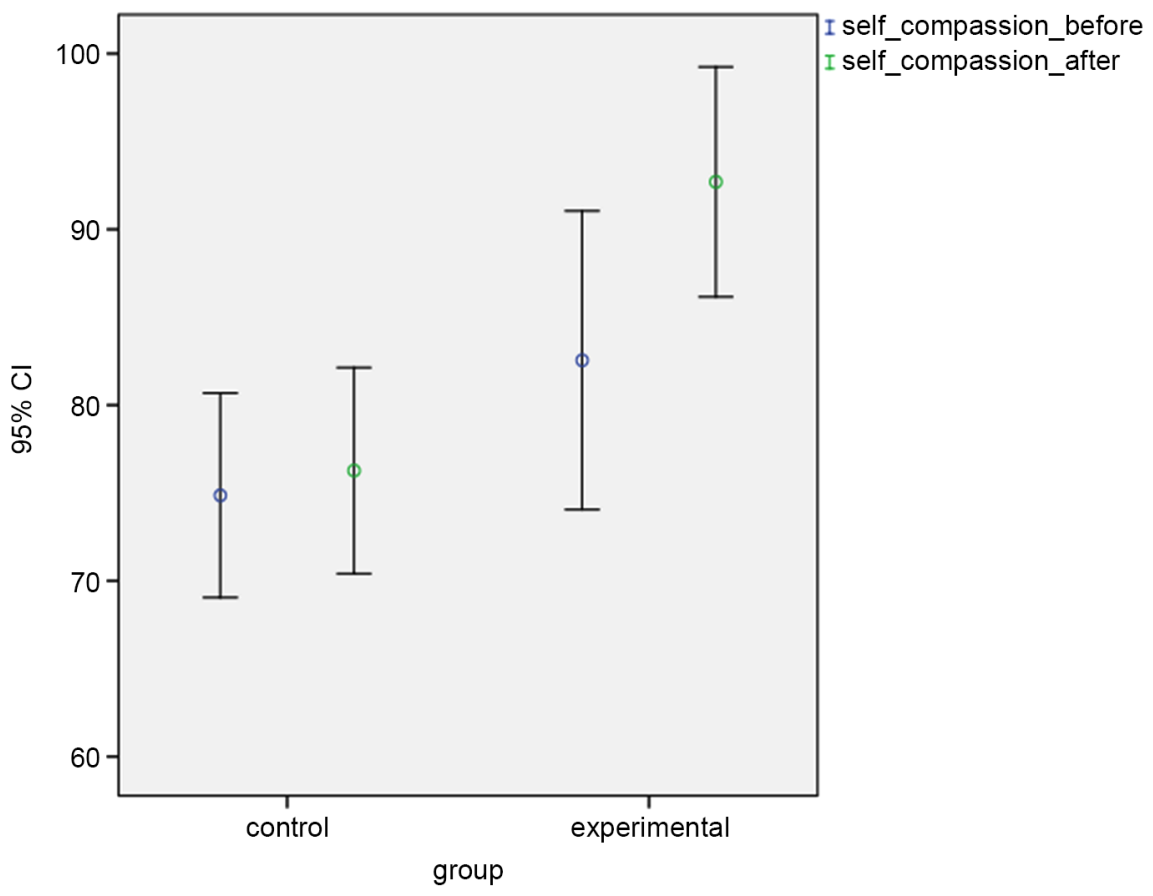

Figure 2. 95\% CI graph of the interaction between group and time. 


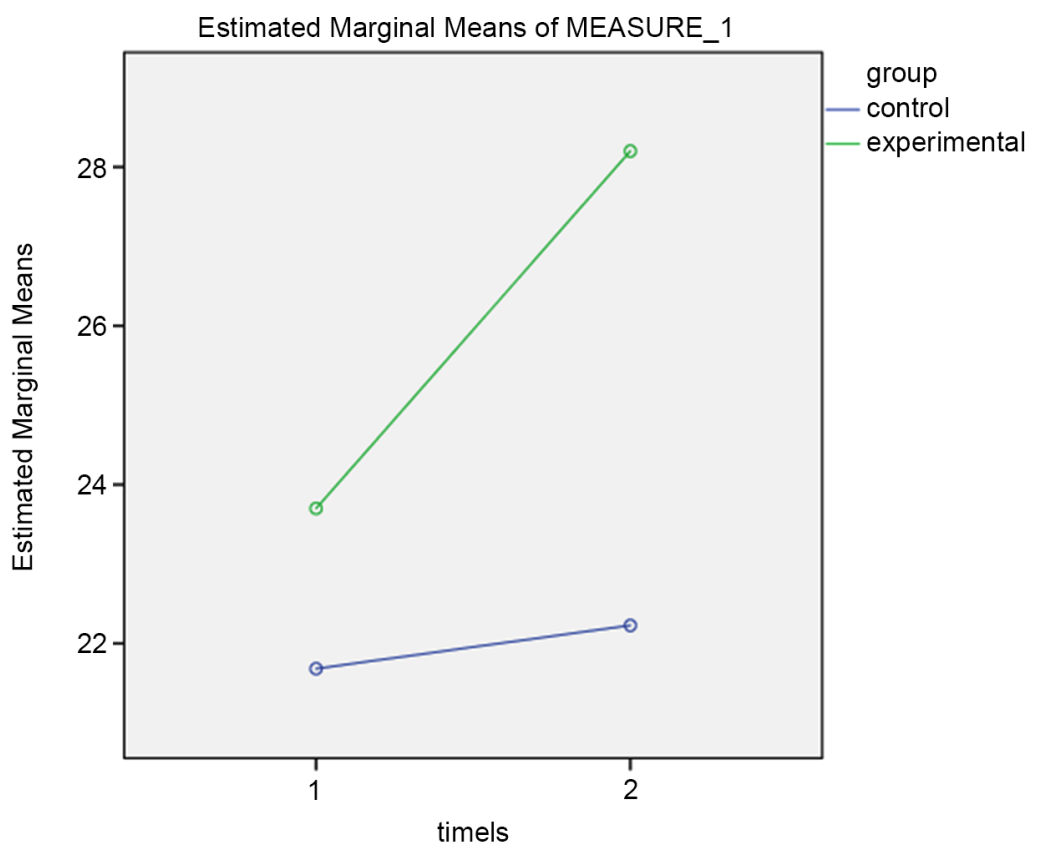

Figure 3. Estimated marginal means for life satisfaction.

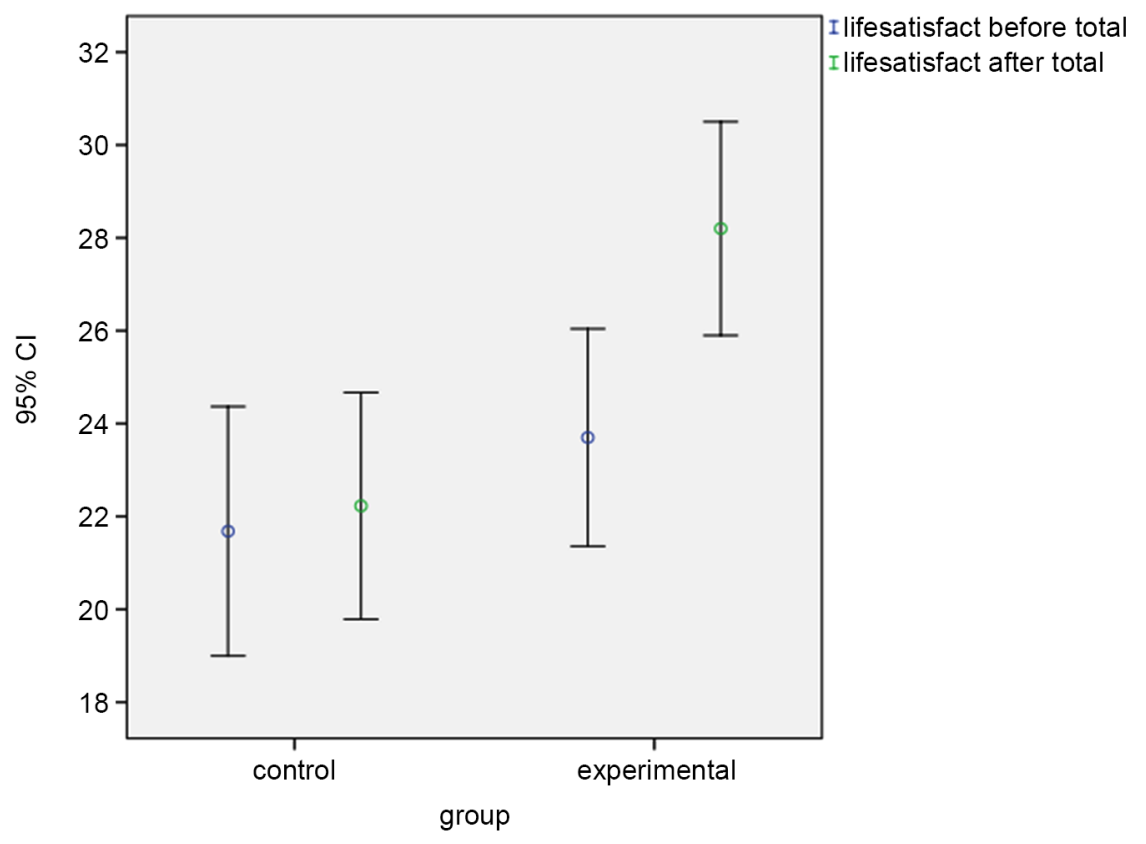

Figure 4. 95\% CI graph of the interaction between group and time.

A two-tailed independent samples t-test showed a significant change between the two groups, self-compassion intervention and control group with the intervention group demonstrating greater scores in life satisfaction rather than the control group $[t(40)=-3.70, p=0.001]$. The homogeneity of variance assumed by Levene's test $(F=1.23, p=0.274)$.

\subsection{Positive Affect}

There was a significant main effect of the time of positive affect (pretest-posttest), 
$F(1,40)=6.70, p=0.013, \mathrm{Eta}^{2}=14(14 \%)$. According to the examination of the estimated marginal means, this effect tells us that if we ignore the group (intervention-control), the time of positive affect (pretest-posttest) will still be rated significantly different (see Figure 5).

There was a significant main effect of group (intervention-control), $F(1,40)=$ $6.24, p=0.017, \mathrm{Eta}^{2}=0.13(13 \%)$. According to the examination of the estimated marginal means, this effect tells us that if we ignore all other variables, the intervention group will be significantly different to control group (see Figure 5).

There was a significant interaction between the time of positive affect (pretestposttest) and the group (intervention-control), $F(1,40)=7.56, p=0.009, \mathrm{Eta}^{2}=$ $0.16(16 \%)$. This effect tells us that the time of positive affect (pretest-posttest) had a different effect on the group (intervention-control). The CI Graph below indicated greater positive affect differences for intervention than the control group (see Figure 6).

A two-tailed independent samples t-test showed a significant change between the two groups, self-compassion intervention and control group with the intervention group demonstrating greater scores in positive affect rather than the control group $[t(40)=-3.79, p=0.001]$. The homogeneity of variance assumed by Levene's test $(F=0.075, p=0.392)$.

\subsection{Negative Affect}

There was a significant main effect of the time of negative affect (pretest-posttest), $F(1,40)=17.69, p<0.001, \mathrm{Eta}^{2}=31(31 \%)$. According to the examination of the estimated marginal means, if we ignore the group (intervention-control), the time of negative affect (pretest-posttest) will still be rated significantly different

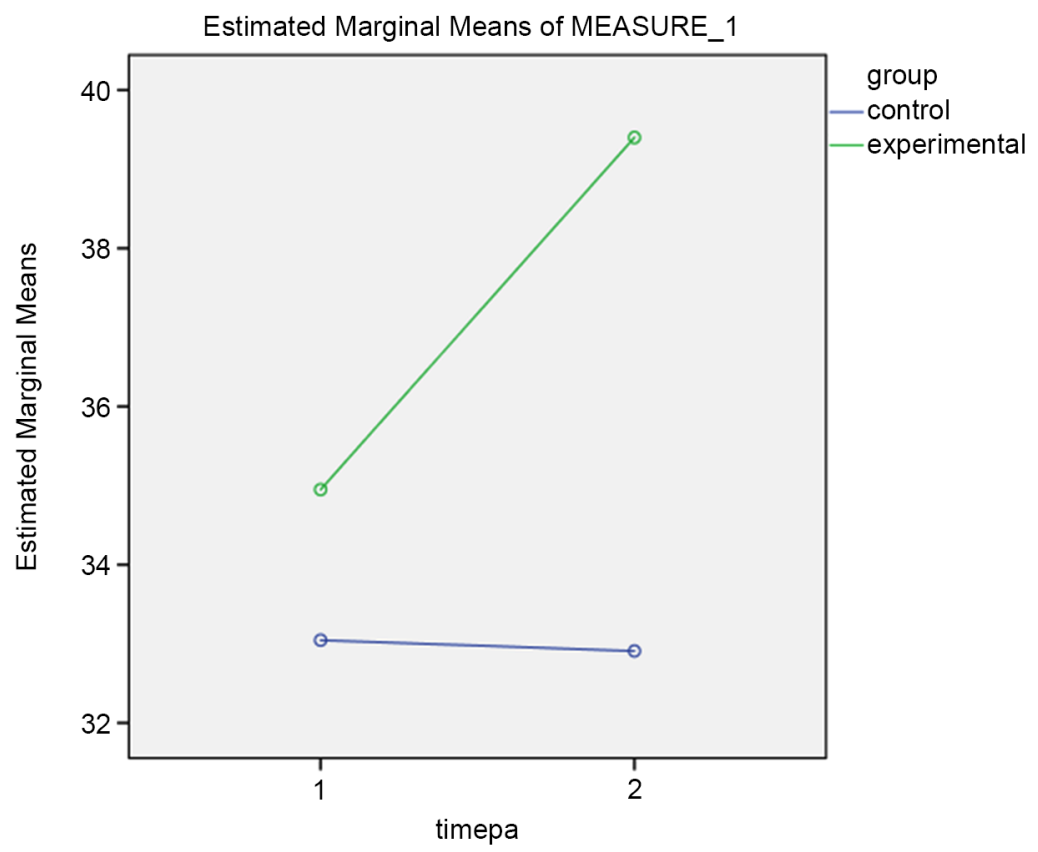

Figure 5. Estimated marginal means for positive affect. 


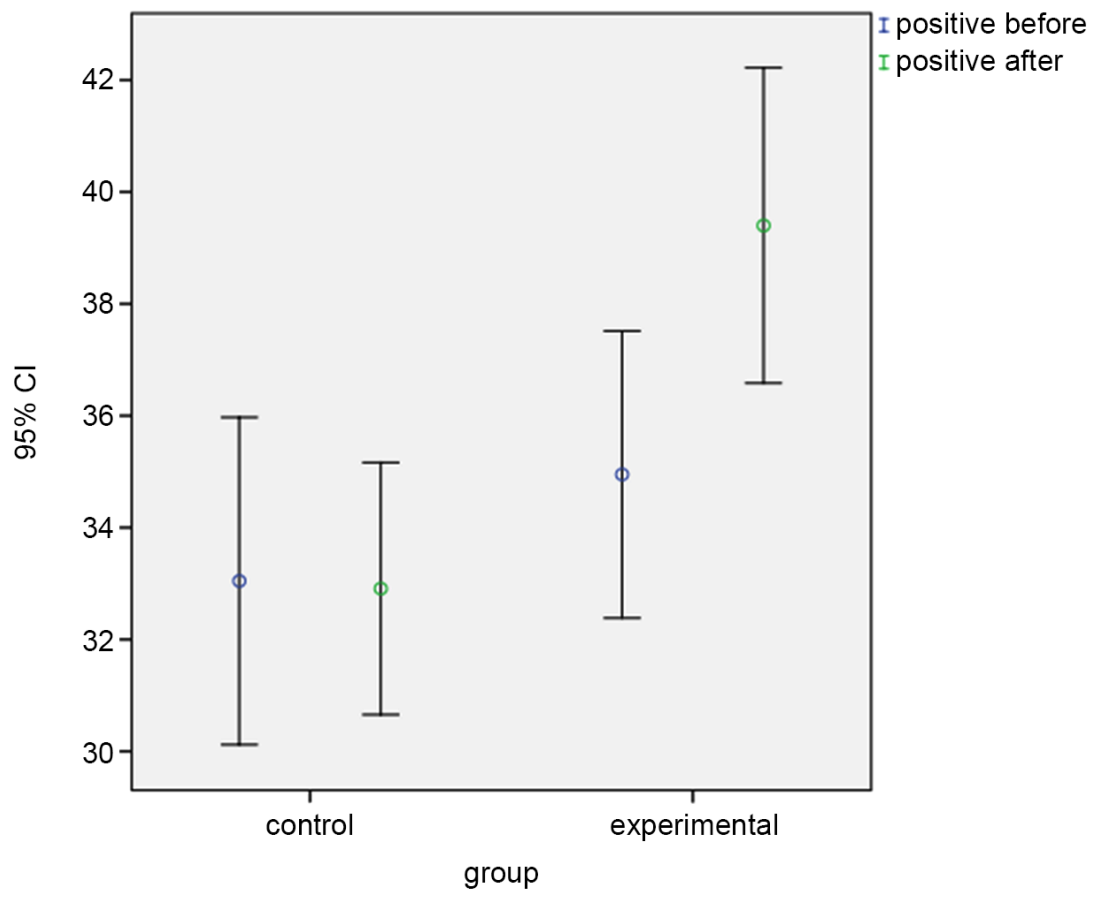

Figure 6. 95\% CI graph of the interaction between group and time.

while, on the other hand, there was a no significant main effect of group (intervention-control), $F(1,40)=0.97, p=0.330, \mathrm{Eta}^{2}=0.02(2 \%)$ (see Figure 7).

There was a significant interaction between the time of negative affect (pretest-posttest) and the group (intervention-control), $F(1,40)=16.74, p<0.001$, $\operatorname{Eta}^{2}=0.29(29 \%)$. This effect shows that the time of negative affect (pretestposttest) had a different effect on the group (intervention-control). The CI Graph below indicated greater negative affect differences in the intervention group rather than the control group (see Figure 8).

A two-tailed independent samples t-test showed a significant change between the two groups, self-compassion intervention and control group with the intervention group demonstrating lower scores in negative affect rather than the control group $[t(40)=2.75, p=0.009]$. The homogeneity of variance assumed by Levene's test $(F=0.421, p=0.520)$.

Finally, a simple linear regression was performed in order to examine whether self-compassion can significantly predict positive affect and the results are presented in Table 3 below. Preliminary analyses were conducted to ensure there was no violation of the assumption of normality and linearity. A significant regression equation was found $(F(1,40)=11.40, p=0.002)$, with an $R^{2}$ of 0.22 . It was proven that participants' self-compassion scores significantly predicted positive affect $(b=0.191, t(40)=3.38, p=0.002)$. Participants with higher selfcompassion scores indicated higher scores on positive affect.

\section{Discussion}

The primary goal of this study was to expand scientific knowledge on the construct of self-compassion by investigating whether self-compassion can significantly 


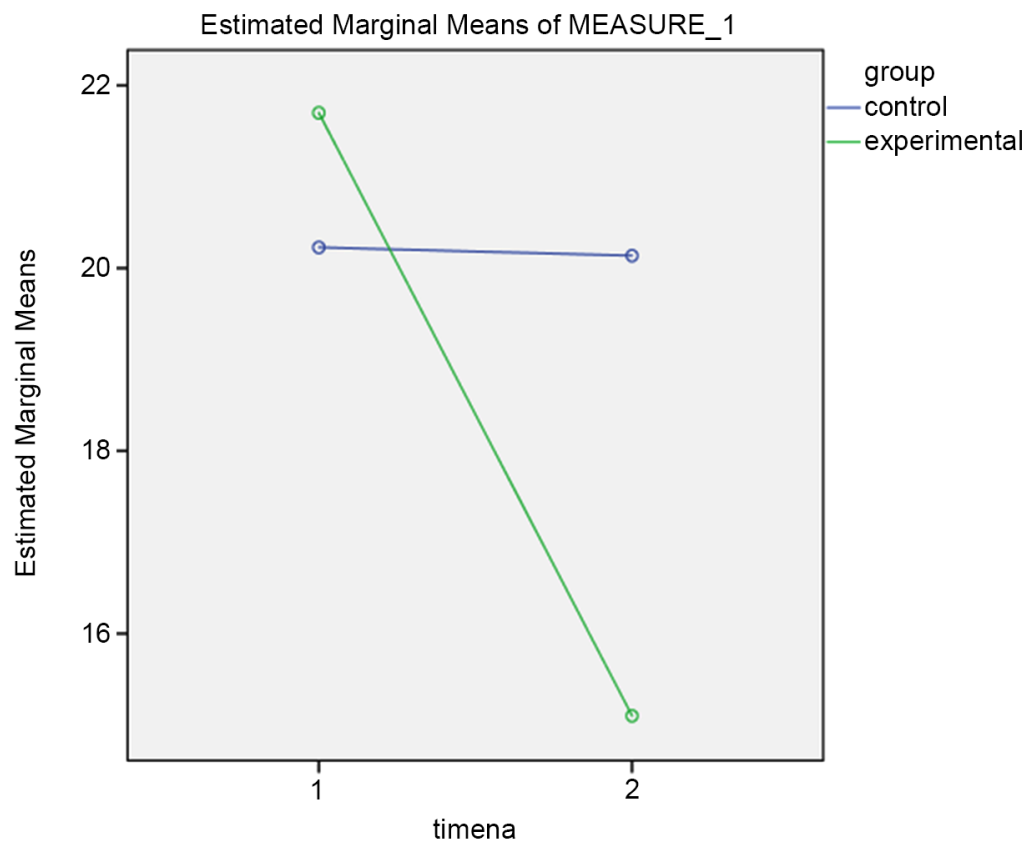

Figure 7. Estimated marginal means for negative effect.

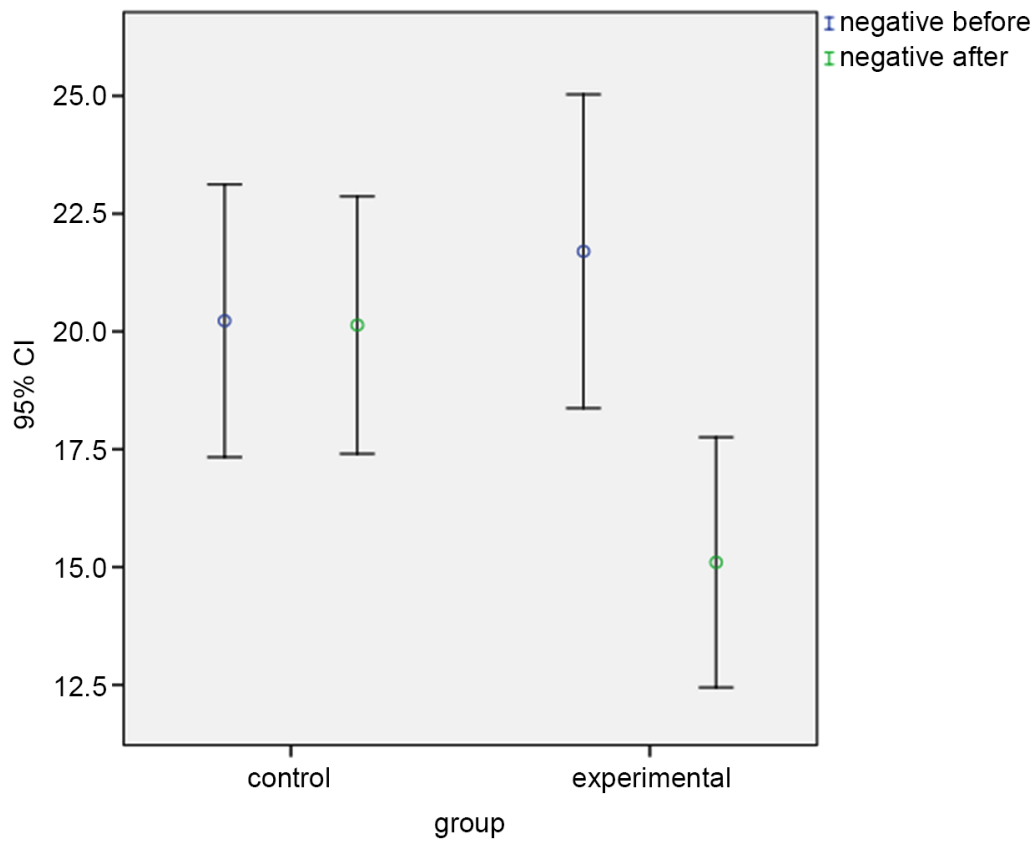

Figure 8. 95\% CI graph of interaction between group and time.

Table 3. Summary of linear regression analysis with self-compassion as predictor of positive effect.

\begin{tabular}{cccccc}
\hline \multirow{2}{*}{ Criterions } & \multicolumn{5}{c}{ Positive Affect } \\
\cline { 2 - 5 } & $\mathrm{B}$ & $\mathrm{SE}$ & $\beta$ & $R^{2}$ & $F$ \\
\hline Self-compassion & 0.19 & 0.57 & $0.47^{*}$ & $0.22^{*}$ & 11.40 \\
\hline
\end{tabular}

Note: $\mathrm{SE}=$ standard error; ${ }^{\star} p<0.05$. 
predict positive affect. Additionally, the secondary purpose of the study entailed the exploration of the effects of a newly developed brief self-compassion intervention on psychological well-being, and more specifically on self-compassion, positive and negative effect, and life satisfaction. The findings are encouraging and suggest that increased self-compassion can significantly predict increased positive effect, as participants' higher levels of self-compassion significantly predicted higher levels of positive affect. Furthermore, in line with our expectations, the results of this study strongly indicated that self-compassion intervention led to an important increase in people's self-compassion levels, life satisfaction levels and positive affect levels, as well as to a decrease in their negative affect levels compared to the control group which indicated no significant differences in those variables. In other words, participants who attended the brief self-compassion intervention program and were trained in order to be more self-compassionate in challenging situations, showed greater improvements in aspects of psychological well-being, before and after the completion of the training.

Of greater importance is that the analyses performed successfully replicated all the findings that the study sought to reproduce. First of all, the present study aimed at examining whether changes in self-compassion on the part of the intervention group could predict changes in positive affect. Indeed, results revealed that increased self-compassion significantly predicted increased positive affect. That means that participants who face everyday challenging situations in a more self-compassionate manner are also to gain more in terms of positive effect, proving that self-compassion is a pivotal factor for the effectiveness of potential interventions. This finding is consistent with previous research (Neff, 2004; Neff \& Germer, 2013) stating that self-compassion constitutes a core predictor of changes in various aspects of psychological well being. Nevertheless, contrary to our results, the research of Smeets et al. (2014) proved that changes in self-compassion did not significantly predict changes in positive affect attributing this absence of prediction to the short nature of the intervention.

Additionally, this study showed that training people in order to treat themselves in a more self-compassionate way when suffering through the 3-week intervention resulted in significant gains in self-compassion scores. First and foremost, this confirms many researchers' viewpoints (Neff \& Costigan, 2014; Shapira \& Mongrain, 2010; Smeets et al., 2014) arguing that self-compassion can be cultivated and learned through brief intervention programs and consequently lead to the enhancement of psychological well-being. However, although Neff \& Germer (2013) through their 8-week intervention program revealed a $43 \%$ increase in self-compassion levels, this does not mean that a brief intervention program cannot successfully promote self-compassion, at least to some extent.

Along with increasing self-compassion, this intervention significantly enhanced participants' life satisfaction levels compared to the control group, which reported no differences. In other words, that means that people who were trained in order to be more self-compassionate, having a non self-critical attitude and a positive perspective towards demanding and difficult situations seem 
to achieve a better life evaluation. This corroborates a plethora of previous evidence (Neely, et al., 2009; Seligowski, Miron, \& Orcutt, 2014; Van Dam, Sheppard, Forsyth, \& Earleywine, 2011; Wei, et al., 2011; Yang, 2016) suggesting that high self-compassion may lead to important life satisfaction benefits, which has also been tested and confirmed through recent intervention plans (Bluth, Roberson, \& Gaylord, 2015; Germer \& Neff, 2013). However, although Smeets and colleagues' (2014) 3-week self-compassion intervention yielded increases in life satisfaction scores for both groups intervention and control group, this study did not find differences in life satisfaction scores for the control group that received no training.

Meeting our expectations, the self-compassion intervention successfully boosted the levels of participants' positive affect and helped minimize the levels of participants' negative affect compared to the control group which showed no changes. Up until now, a large body of studies has highlighted that self-compassion promotes positive affect and reduces negative affect (Neff, Rude, \& Kirkpatrick, 2007; Neff \& Vonk, 2009; Krieger et al., 2015), examining it through questionnaire distribution. Nevertheless, only one study (Smeets et al., 2014) seems to have investigated this effect through a brief 3-week self-compassion intervention. Contrary to the findings of the present study, Smeets et al. (2014) found no significant changes in positive and negative affect for the self-compassion intervention group attributing again this lack of association between self-compassion and affect to the brief duration of the psycho-educational training program. Consequently, those results pointed to the need for the implementation of further future intervention focusing on self-compassion and positive and negative affect interaction (Smeets et al., 2014; Barnard \& Curry, 2011), which is something that this study attempted to explore.

Therefore, the results of this study are in accordance with previous findings that have proved that higher scores on self-compassion seem to lead, among other things, to higher levels on positive affect and life satisfaction (Heffernan, Griffin, McNulty \& Fitzpatrick, 2010; Hollis-Walker \& Colosimo, 2011; Neff, Rude, \& Kirkpatrick, 2007; Neff, 2009) and to a less stressful experience of negative feelings (Leary et al., 2007). To state it differently, people who are more self-compassionate have the tendency to make more positive automatic thoughts (Arimitsu \& Hofmann, 2015) and that consequently results in higher levels of life satisfaction. Hence, they are more capable of dealing more effectively and coping better with their possible failures, mistakes and personal weaknesses, as they maintain a positive attitude towards those conditions.

\subsection{Implications}

Overall, it was extensively supported that high self-compassion is a core psychological asset for the public. The results of the present study indicated that self-compassion as a life attitude, as an ability and a learned behavior can be an effective tool towards the enhancement of psychological well being. Researchers are therefore encouraged to promote the use of self-compassion in order to cul- 
tivate participants' self-compassion, life satisfaction and positive effect, eliminating negative effect. More specifically, the implications of the current study are evident on both a practical and a theoretical level. From a theoretical perspective, the study expands scientific knowledge related to the notion of self-compassion and to its effects on a range of aspects of psychological well-being. From a practical perspective, the study underlines the importance of brief self-compassion psycho-educational training programs in relation to variables of well-being, such as positive and negative affect and life satisfaction. It seems that there are some compelling reasons for the scientific community to embrace the brief version of self-compassion intervention programs, incorporating it in its training sessions as it constitutes a less time consuming and a more cost effective method of evaluation, standing in sharp contrast to the longer intervention programs and having similarly effective results; thus assisting researchers to apply such kind of interventions more often and to a larger audience.

\subsection{Limitations and Future Research Directions}

As it may be easily understood, this study has a few limitations that offer important directions for future research. Most notably the utilization of self-report measures of self-compassion, life satisfaction and positive and negative affect comes with both advantages and disadvantages. Self-report questionnaires offer some insight to the inner experiences of individuals that could not be obtained by other measures (Paulhus \& Vazire, 2007). In addition, self-compassion, life satisfaction and affect are personal emotional experiences that do not necessarily lead to observable reactions. Nonetheless, self-reports are subjected to bias (Paulhus \& Vazire, 2007). So, it would be a good idea for researchers to think of alternative multi-method ways to measure self-compassion, life satisfaction and affect to further confirm our findings, such as the utilization of qualitative data (through calendars, assessments etc) or behavioral measures.

The research in point was also based on students of Social Sciences whose ethnic composition was $100 \%$ Greek. Thus, our results might not be generalizable to other groups and populations with quite different characteristics (e.g. different age, different ethnic and cultural backgrounds, clinical or specific populations) and there is the need for further research. Furthermore, the number of females participating in the study $(\mathrm{N}=27)$ was greater than that of males $(\mathrm{N}=$ $15)$, which highlights the need for future investigation on gender differences regarding the changes of self-compassion. Moreover, although participants' demographics characteristics were a factor that was taken into consideration, it did not encompass the effect of religious belief. Neff et al. (2008) found that participants of Thailand were strongly influenced by Buddhism, indicating higher scores on self-compassion, compared to participants of Taiwan region and the United States. Thus, future studies should focus on how people's religious beliefs may influence the results of the intervention.

Additionally, it should be noticed that no follow-up measurements were included in this study in order for maintenance of the therapeutic gains to be en- 
sured. However, Shapira \& Mongrain (2010) as well as Neff \& Germer (2013) revealed that a brief intervention program can potentially lead to long-lasting benefits in self-compassion, lasting for at least one year. The effects of the duration of the current intervention, though, should still be investigated in the future.

Finally, another limitation of this study can be said to be the concurrent assessment of the constructs, and so there is still the issue of causation which should probably be addressed by longitudinal designs.

\section{References}

Arimitsu, K., \& Hofmann, S. G. (2015). Cognitions as Mediators in the Relationship between Self-Compassion and Affect. Personality and Individual Differences, 74, 41-48. https://doi.org/10.1016/j.paid.2014.10.008

Baer, R. A., Lykins, E. L. B., \& Peters, J. R. (2012). Mindfulness and Self-Compassion as Predictors of Psychological Wellbeing in Long-Term Meditators and Matched Non Meditators. The Journal of Positive Psychology, 7, 230-238.

Barnard, L. K., \& Curry, J. F. (2011). Self-Compassion: Conceptualizations, Correlates, \& Interventions. Review of General Psychology, 15, 289-303.

Birnie, K., Speca, M., \& Carlson, L. E. (2010). Exploring Self-Compassion and Empathy in the Context of Mindfulness-Based Stress Reduction (MBSR). Stress and Health, 26, 359-371. https://doi.org/10.1002/smi.1305

Bluth, K., Roberson, P. N. E., \& Gaylord, S. A. (2015). A Pilot Study of a Mindfulness Intervention for Adolescents and the Potential Role of Self-Compassion in Reducing Stress. Explore: The Journal of Science and Healing, 11, 292-295.

https://doi.org/10.1016/j.explore.2015.04.005

Bolier, L., Haverman, M., Westerhof, G. J., Riper, H., Smit, F., \& Bohlmeijer, E. (2013). Positive Psychology Interventions: A Meta-Analysis of Randomized Controlled Studies. BMC Public Health, 13, 119.

Diener, E., Emmons, R. A., Larsen, R. J., \& Griffin, S. (1985). The Satisfaction with Life Scale. Journal of Personality Assessment, 49, 71-75. https://doi.org/10.1207/s15327752jpa4901_13

Germer, C. K. (2009).The Mindful Path to Self-Compassion. New York, NY: Guilford Press.

Germer, C. K., \& Neff, K. D. (2013). Self-Compassion in Clinical Practice. Journal of Clinical Psychology, 69, 856-867. https://doi.org/10.1002/jclp.22021

Giannopoulos, V. L., \& Vella-Brodrick, D. A. (2011). Effects of Positive Interventions and Orientations to Happiness on Subjective Well-Being. The Journal of Positive Psychology, 6, 95-105. https://doi.org/10.1080/17439760.2010.545428

Heffernan, M., Griffin, M., McNulty, S., \& Fitzpatrick, J. J. (2010). Self-Compassion and Emotional Intelligence in Nurses. International Journal of Nursing Practice, 16, 366373. https://doi.org/10.1111/j.1440-172X.2010.01853.x

Hollis-Walker, L., \& Colosimo, K. (2011). Mindfulness, Self-Compassion, and Happiness in Non-Meditators: A Theoretical and Empirical Examination. Personality and Individual Differences, 50, 222-227. https://doi.org/10.1016/j.paid.2010.09.033

Krieger, T., Hermann, H., \& Zimmermann, J., \& Holtforth, M. G. (2015). Associations of Self-Compassion and Global Self-Esteem with Positive and Negative Affect and Stress Reactivity in Daily Life: Findings from a Smart Phone Study. Personality and Individual Differences, 87, 288-292. https://doi.org/10.1016/j.paid.2015.08.009 
Leary, M. R., Tate, E. B., Adams, C. E., Allen, A. B., \& Hancock, J. (2007). Self-Compassion and Reactions to Unpleasant Self-Relevant Events: The Implications of Treating Oneself Kindly. Journal of Personality and Social Psychology, 92, 887-904. https://doi.org/10.1037/0022-3514.92.5.887

MacBeth, A., \& Gumley, A. (2012). Exploring Compassion: A Meta-Analysis of the Association between Self-Compassion and Psychopathology. Clinical Psychology Review, 32, 545-552. https://doi.org/10.1016/j.cpr.2012.06.003

Malikiosi-Loizos, M., \& Anderson, L. R. (1994). Reliability of a Greek Translation of the Life Satisfaction Index. Psychological Reports, 74, 1319-1322. https://doi.org/10.2466/pr0.1994.74.3c.1319

Mantzios, M., Wilson, J. C., \& Giannou, K. (2015). Psychometric Properties of the Greek Versions of the Self-Compassion and Mindful Attention and Awareness Scales. Mindfulness, 6, 123-132. https://doi.org/10.1007/s12671-013-0237-3

Neely, M. E., Schallert, D. L., Mohammed, S. S., Roberts, R. M., \& Chen, Y. (2009). SelfKindness When Facing Stress: The Role of Self-Compassion, Goal Regulation, and Support in College Students' Well-Being. Motivation and Emotion, 33, 88-97. https://doi.org/10.1007/s11031-008-9119-8

Neff, K. D. (2003a). The Development and Validation of a Scale to Measure Self-Compassion. Self and Identity, 2, 223-250. https://doi.org/10.1080/15298860309027

Neff, K. D. (2003b). Self-Compassion: An Alternative Conceptualization of a Healthy Attitude toward Oneself. Self and Identity, 2, 85-102. https://doi.org/10.1080/15298860309032

Neff, K. D. (2004). Self-Compassion and Psychological Well-Being. Constructivism in the Human Sciences, 9, 27-37.

Neff, K. D. (2009). The Role of Self-Compassion in Development: A Healthier Way to Relate to Oneself. Human Development, 52, 211-214. https://doi.org/10.1159/000215071

Neff, K. D. (2012). The Science of Self-Compassion. In C. Germer, \& R. Siegel (Eds.), Compassion and Wisdom in Psychotherapy (pp. 79-92). New York, NY: Guilford Press.

Neff, K. D., \& Costigan, A. P. (2014). Self-Compassion, Wellbeing, and Happiness. 114119.

Neff, K. D., \& Germer, C. K. (2013). A Pilot Study and Randomized Controlled Trial of the Mindful Self-Compassion Program. Journal of Clinical Psychology, 69, 28-44. https://doi.org/10.1002/jclp.21923

Neff, K. D., \& Lamb, L. M. (2009). Self-Compassion. In S. Lopez (Ed.), The Encyclopedia of Positive Psychology (pp. 864-867). Oxford: Blackwell Publishing Ltd.

Neff, K. D., \& Vonk, R. (2009). Self-Compassion versus Global Self-Esteem: Two Different Ways of Relating to Oneself. Journal of Personality, 77, 23-50. https://doi.org/10.1111/j.1467-6494.2008.00537.x

Neff, K. D., Kirkpatrick, K. L., \& Rude, S. S. (2007). Self-Compassion and Adaptive Psychological Functioning. Journal of Research in Personality, 41, 139-154.

https://doi.org/10.1016/j.jrp.2006.03.004

Neff, K. D., Pisitsungkagarn, K., \& Hsieh, Y. P. (2008). Self-Compassion and Self-Construal in the United States, Thailand, and Taiwan. Journal of Cross-Cultural Psychology, 39, 267-285. https://doi.org/10.1177/0022022108314544

Neff, K. D., Rude, S. S., \& Kirkpatrick, K. L. (2007). An Examination of Self-Compassion in Relation to Positive Psychological Functioning and Personality Traits. Journal of Research in Personality, 41, 908-916. https://doi.org/10.1016/j.jrp.2006.08.002

Paulhus, D. L., \& Vazire, S. (2007). The Self-Report Method. In R.W. Robins, R. C. Fraley, 
\& R. F. Krueger (Eds.), Handbook of Research Methods in Personality Psychology (pp. 224-239). New York, NY: The Guilford Press.

Seligman, M. E. P., Steen, T. A., Park, N., \& Peterson, C. (2005). Positive Psychology Progress, Empirical Validation of Interventions. American Psychologist, 60, 410-421. https://doi.org/10.1037/0003-066X.60.5.410

Seligowski, A. V, Miron, L. R., \& Orcutt, H. K. (2014). Relations among Self-Compassion, PTSD Symptoms, and Psychological Health in a Trauma-Exposed Sample. New York, NY: Springer Science + Business Media.

Shapira, L. B., \& Mongrain, M. (2010). The Benefits of Self-Compassion and Optimism Exercises for Individuals Vulnerable to Depression. The Journal of Positive Psychology, 5, 377-389. https://doi.org/10.1080/17439760.2010.516763

Smeets, E., Neff, K., Alberts, H., \& Peters, M. (2014). Meeting Suffering with Kindness: Effects of a Brief Self-Compassion Intervention for Female College Students. Journal of Clinical Psychology, 70, 794-807. https://doi.org/10.1002/jclp.22076

Van Dam, N. T., Sheppard, S. C., Forsyth, J. P., \& Earleywine, M. (2011). Self-Compassion Is a Better Predictor Than Mindfulness of Symptom Severity and Quality of Life in Mixed Anxiety and Depression. Journal of Anxiety Disorders, 25, 123-130.

https://doi.org/10.1016/j.janxdis.2010.08.011

Watson, D., Clark, L. A., \& Tellegen, A. (1988). Development and Validation of Brief Measures of Positive and Negative Affect: The PANAS Scales. Journal of Personality and Social Psychology, 54, 1063-1070. https://doi.org/10.1037/0022-3514.54.6.1063

Wei, M., Liao, K. Y., Ku, T., \& Shaffer, P. A. (2011). Attachment, Self-Compassion, Empathy, and Subjective Well-Being among College Students and Community Adults. Journal of Personality, 79, 191-221. https://doi.org/10.1111/j.1467-6494.2010.00677.x

Yang, X. (2016). Self-Compassion, Relationship Harmony, versus Self-Enhancement: Different Ways of Relating to Well-Being in Hong Kong Chinese. Personality and Individual Differences, 89, 24-27. https://doi.org/10.1016/j.paid.2015.09.006

Yang, Y., Zhang, M., \& Kou, Y. (2016). Self-Compassion and Life Satisfaction: The Mediating Role of Hope. Personality and Individual Differences, 98, 91-95. https://doi.org/10.1016/j.paid.2016.03.086

Zessin, U., Dickhauser, O., \& Garbade, S. (2015). The Relationship between Self-Compassion and Well-Being: A Meta-Analysis. Applied Psychology. Health and Well-Being, 7, 340-364. https://doi.org/10.1111/aphw.12051 
Submit or recommend next manuscript to SCIRP and we will provide best service for you:

Accepting pre-submission inquiries through Email, Facebook, LinkedIn, Twitter, etc. A wide selection of journals (inclusive of 9 subjects, more than 200 journals)

Providing 24-hour high-quality service

User-friendly online submission system

Fair and swift peer-review system

Efficient typesetting and proofreading procedure

Display of the result of downloads and visits, as well as the number of cited articles Maximum dissemination of your research work

Submit your manuscript at: http://papersubmission.scirp.org/

Or contact psych@scirp.org 